\title{
Students' Perception towards COVID-19 Vaccination Program in Bangladesh: A Study on University Students
}

\author{
Bikram Biswas ${ }^{\text {**, Mohammad Nur Ullah', Sajib Kumar Roy }}{ }^{3}$, Falguni Roy ${ }^{4}$, \\ Muhammad Ridwan ${ }^{5}$ \\ ${ }^{1,4}$ Noakhali Science and Technology University, Noakhali-3814, Bangladesh \\ ${ }^{2}$ Department of Public Administration, Bangladesh University of Professionals, Mirp ur Cantonment, Dhaka- \\ 1216, Bangladesh \\ ${ }^{3}$ Hajee Mohammad Danesh Science and Technology University, Dinajpur-5200, Bangladesh \\ ${ }^{5}$ Universitas Islam Negeri Sumatera Utara, Indonesia
}

\begin{abstract}
After a long waited span, the whole world could see the ray of covid-19 vaccine to resist the planet to watch the death procession. But some country people especially the people of Bangladesh keep them aside to take the vaccination. This study aims to understand the perception towards the COVID-19 vaccination program in Bangladesh and the targeted subject is the university student as they are suffering highly depression nowadays. Higher education has been affected globally as a result of the COVID-19 pandemic in 223 countries. Moreover, for this pandemic situation, the university students can not complete their graduation which binds them to enter their professional career. Alike all of the developed countries, as well as developing countries, Bangladesh, also considered vaccination as an effective measure to protect the peoples from the Covid-19virus. This study targeted three psychological factors of the university students and surveyed 322 students from the different universities in Bangladesh to understand their perception regarding vaccines. Moreover, it is seen that most of the students doubt the effectiveness of the vaccine which interrupts them from taking the vaccine willingly.
\end{abstract}

Keywords perception; Covid-19; vaccination; University Students; Bangladesh

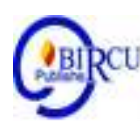

\section{Introduction}

Vaccines are an important tool for halting the spread of the pandemic such as COVID-19, influenza, etc. More than 100 candidates were in the run to produce the COVID-19 vaccine (Pogue et al 2020). Though the COVID-19 vaccine was launched on a fast track, it took entry in the market just nine months after the virus was identified (Bhartiya et al, 2021). Several COVID-19 vaccines have been approved and are being applied in various parts of the world. To develop a COVID-19 vaccine to stop the disease's spread and devastating consequences by covering the maximum variant of the virus, the racing between candidates is still on (Felter, 2021 and Chan et al., 2015) and as the pandemic progresses, more successful latest vaccines are likely to be produced. However, it is essential to assess the people acceptance of COVID-19 vaccinations for effectively delivering vaccines (Reiter et al, 2020) as some researchers observed that the large population has relatively high vaccine hesitancy on current vaccinations and also, the coverage of vaccination is not adequate (van Doremalen et al 2020; Harapan et al. 2019).

On January 27, 2021, the authority of Bangladesh decided to use the Covidshield vaccine of India, and Runu (a nurse) became the first recipient of it (Dhaka Tribune, 
2020). However, there is widespread opposition to take vaccinations among Bangladesh's mass people. A portion of Bangladeshi citizens is hesitant to take vaccines and according to Islam et al., 2021, all educational institutions have been closed since March 16, 2020. So, it is necessary to get vaccinated all the students so that universities and colleges can run their program as the previous mode in Bangladesh. But the question is whether they can take the vaccine or not? What are their views on the vaccine program? What are the variables that influence their decisions? To answer these questions, this paper aims to identify the university students' perception of the COVID-19 vaccination program in Bangladesh.

\section{Review of Literatures}

\subsection{Finding Gap}

Ali et al, (2020) stated that the people used a variety of information sources to know about the COVID-19, including television, radio, newspapers, social media, friends, coworkers, healthcare providers, scientists, governments, and so on. Since such sources of knowledge have the potential to influence the people's acceptance or rejection of COVID19 vaccines, it is critical to disseminate clear and reliable information about vaccine safety and efficacy to gain the confidence of the public, especially those who are reluctant and skeptical of taking vaccine (Siegrist, \& Zingg 2014). Usually, people's trust regarding the vaccine is the crucial key to the success of any potential national vaccination campaign. On the other hand, Bhartiya et al. (2021) conducted a study in West India and discovered that nearly two-thirds of young adults aged 18 to 40 years were unaware of the COVID-19 vaccines' availability. Furthermore, nearly 79 percent of study participants said they would take the vaccine if it were available and only $2 \%$ said they would not. Synnott (2021) directed a study titled "College Students' COVID-19 Vaccine Hesitancy" where the following responses were collected based on the survey question, "Will you be vaccinated for the coronavirus when vaccines are available?" 299 people (50.6 percent) responded positively, 176 people $(29.8 \%)$ were reacted negatively, and 114 people (19.3\%) said they weren't aware. The students' statement on why they would refuse to be vaccinated or why they were uncertain was that they wanted more clear and authentic information. A study titled 'COVID-19 knowledge, attitude, and practice among medical undergraduate students in Baghdad City' was conducted by Khalil et al. (2020) where he discovered the students' overall awareness of COVID-19 is 91.8 percent and social media was serving as the primary source of learning (36 percent). More than $90 \%$ and three-quarters of students had a good outlook toward the pandemic and were taking preventive steps. Furthermore, more than half of the students were pleased with the local health authorities combatting strategy during COVID-19. On the other side, Lucia et al. (2020) found that virtually all participants had favorable attitudes about vaccines. We have only found one paper regarding Bangladesh perspectives titled 'Information, attitudes, and expectations towards COVID-19 vaccinations: a cross-sectional group survey in Bangladesh' conducted by Islam et al. (2021). The results indicate the general population in Bangladesh has insufficient knowledge but more optimistic attitudes toward the COVID-19 vaccine. 
We could see from the above discussion of literature reviews that some studies have been conducted in the international arena about COVID-19 vaccination in terms of awareness, perception, and hesitation, and we found literature in Bangladesh that focuses on community peoples' overall knowledge and attitudes about it. We have seen some country-specific studies on university or college students about their knowledge and perception and their hesitancy of the covid-19 vaccination program. This kind of study is missing in the Bangladesh context. With this backdrop, this paper is a micro-study of University Students' Perception of the COVID-19 vaccination program in Bangladesh.

\subsection{The State of COVIID-19 in Bangladesh}

Most of the countries in the world in a state of flux due to COVID-19 in terms of socio-economics, socio-politics, culture, education, food and nutrition, and so on. The epicenters of the coronavirus are now most of the cities around the world, as they are recognized as the gateway to the international arena (Asante and Mills, 2020). As of April 1, 2021, this deadly virus had infected $129,688,822$ people worldwide, killing 2,831,463 people and in Bangladesh, the total identified corona cases are 617,764 and deaths are 9,105 (Worldometer, 2021, until April 01). Bangladesh is suffering from the extreme effects of COVID-19, which is causing the country's socio-economic situation to deteriorate. Since March 17, 2020, the government of Bangladesh avoids large-scale shipments to reduce the affected cases and all the educational institutions have been closed. Also, large-scale gatherings have been banned since March 26, 2020 (WHO, 2020). All public and private offices were closed during the prohibition except emergency services such as hospitals, police stations, municipal administration, other related government offices, local vegetable, and fish markets. Bangladesh has adhered to World Health Organization recommendations, such as the Mask Protocol, since May 2020, and the lockdown steps have been relaxed for economic growth (Haque, 2020). The infection rate continues to increase as a result of the less strict lockdown protocol and Bangladesh is now ranking 15th in terms of COVID-19 infections. Without proper execution of the vaccination program, Bangladesh could be place upstairs in the ranking.

\subsection{COVID-19 Vaccination: International Perspectives}

The global effort to develop and distribute an effective vaccine for COVID-19 disease has already yielded some promising options. Within a year, governments, multilateral organizations, and private companies invested billions of dollars to create successful vaccines for it (Felter, 2021). More than 400.1 million vaccine doses have been delivered worldwide as of March 18, 2021, equating to 5.2 doses per 100 people. At least 143 countries and territories have administered more than 409 million doses of a COVID19 vaccine, according to CNN Health, barely a year after the first Covid-19 case was identified in China. There is also a significant disparity between vaccination systems in various nations (Holder, 2021). According to Our World in Statistics, ten different vaccines are used around the world. The Pfizer-BioNTech vaccine, which is $95 \%$ effective in minimizing coronavirus infections, is now used in 76 countries. Several countries have given their consent to vaccines but have yet to start prescribing them (Holder, 2021). The vaccine distribution strategy varies by region. Some proponents have called for vaccinating as many individuals as possible, while others have sought to prioritize vaccinating disadvantaged groups (CNN Health, March 19, 2021). Furthermore, the acceptability of a newly introduced vaccine is an important factor to consider with its 
coverage within the population for an effective immunization program (Bhartiya et al, 2021). Mannan and Farhana published a report in 2020 that shows the global acceptance rate of COVID-19 vaccination.

Table 1. Acceptance of COVID-19 Vaccine in Africa, Asia and Australia

\begin{tabular}{|l|c|l|c|l|c|}
\hline \multicolumn{1}{|c|}{ Africa } & $\boldsymbol{\%}$ & \multicolumn{1}{c|}{ Asia } & Australia & \% \\
\hline Algeria & 66.32 & Afghanistan & 47.22 & Australia & 89.88 \\
\hline Egypt & 43.55 & Bangladesh & 49.81 & Fiji & 87.21 \\
\hline Botswana & 71.23 & China & 87.42 & New Zealand & 88.44 \\
\hline Kenya & 61.33 & India & 73.85 & Kiribati & 89.84 \\
\hline Libya & 49.63 & Japan & 71.44 & Nauru & 88.27 \\
\hline Mali & 62.44 & Malaysia & 52.67 & Palau & 89.22 \\
\hline Mauritius & 82.76 & Saudi Arabia & 51.11 & $\begin{array}{l}\text { Papua New } \\
\text { Gene }\end{array}$ & 91.91 \\
\hline Morocco & 48.44 & Singapore & 66.77 & Solomon Islands & 92.55 \\
\hline Nigeria & 61.54 & South Korea & 76.23 & Tonga & 92.88 \\
\hline South Africa & 79.26 & Turkey & 59.21 & Tuvalu & 90.45 \\
\hline
\end{tabular}

Source: Mannan and Farhana, 2020

Table 2. Acceptance of COVID-19 Vaccine in North America, South America and Europe

\begin{tabular}{|l|c|l|c|l|c|}
\hline \multicolumn{1}{|c|}{ North America } & $\%$ & South America & $\boldsymbol{\%}$ & \multicolumn{1}{c|}{ Europe } & \% \\
\hline Canada & 66.55 & Argentina & 81.33 & England & 69.33 \\
\hline Cuba & 77.89 & Brazil & 86.24 & Belgium & 60.44 \\
\hline $\begin{array}{l}\text { Dominican } \\
\text { Republic }\end{array}$ & 79.49 & Bolivia & 82.77 & Germany & 65.22 \\
\hline El Salvador & 71.81 & Chile & 79.21 & Italy & 68.44 \\
\hline Guatemala & 74.99 & Colombia & 81.77 & France & 51.89 \\
\hline Jamaica & 70.98 & Ecuador & 70.22 & Poland & 52.33 \\
\hline Mexico & 73.25 & Paraguay & 67.66 & Spain & 72.45 \\
\hline Nicaragua & 81.22 & Peru & 77.77 & Sweden & 52.66 \\
\hline Panama & 87.44 & Uruguay & 75.57 & Switzerland & 60.21 \\
\hline USA & 74.77 & Venezuela & 74.76 & Russia & 51.34 \\
\hline
\end{tabular}

Source: Mannan and Farhana, 2020

\subsection{COVID-19 Vaccination: Bangladesh Perspectives}

The COVID-19 vaccination campaign in Bangladesh has begun with the aim to administer over 30 million doses over the next few months in the capital, Dhaka (Hassan, 2021). Bangladesh got seven million doses of the Oxford-AstraZeneca vaccine where two million as a gift from India, and five million via a deal with India's Serum Institute (Arab News, 07 February 2021, https://arab.news/8d2u6). On the first day of the vaccination campaign, Feb. 7, a total of 31,160 people who had enrolled received their first dose of the vaccine (Uttam, 2021). But according to daily star, a major number of people of Bangladesh are dubious to take the vaccine from India lest they should be infected (The Daily Star, 2021). On the other side, a global study of potential COVID-19 vaccine acceptance demonstrates that $48 \%$ of the subjected populations were pixelated about taking the vaccine (Lazarus et al, 2020). However, Bangladesh has been ahead of other European Union nations, which have yet to obtain their mutual vaccine consignment, since 
the beginning of the inoculation drive on February 7. Bangladesh immunized over 4.5 million people between March 16 and March 16, 2021, according to Our World in Data, 2021. The vaccination program will last the whole year and people have to register themselves at the vaccine centers through a web application named "Surokkha". After registering, people would be able to get their vaccines in their chosen centers (The Times of India, 2021). Despite the enormous progress, Church officials blamed low vaccine registration on a lack of knowledge, misinformation, and bad publicity. There were posts on social media about possible vaccine side effects and challenging registration and vaccination locations (Uttam, 2021).

\section{Research Methods}

This study is purely descriptive. This empirical analysis was performed by using both qualitative and quantitative approaches and data has been collected from both primary and secondary sources. Primary data was collected from the students of different universities through an online survey which included structured questions. Secondary data was gathered from a variety of sources including books, journals, blogs, web sources, and newspapers. The research used three-point Likert scale instruments to examine student's perception of the COVID-19 vaccination program in Bangladesh. A purposive sampling technique was used to perform the analysis. The sample for this analysis is $\mathrm{N}=322$ participants.

For this study, the questionnaire contains three basic parts i.e. personal information, knowledge, attitudes, and perceptions. Three-point Likert scale denoted as Agree (A) Neutral (N) and Disagree (D) and YN (Yes, No), and true-false questions are used to fulfill the study objectives. It was an online survey for collecting primary data, so the questionnaire was constructed in Google Form. SPSS, MS Word, and MS Excel were used to tabulate, process, and analyze the data collected from various respondents through the online survey. Moreover, the data was analyzed using both nominal and ordinal measurements.

\section{Results and Discussion}

\subsection{Results}

a. Background Information of Respondents

This segment contains the basic information about the respondents who took part in the survey. Table- 3 shows the outputs of the questions regarding to gender, age, and level of education.

\begin{tabular}{|c|l|r|}
\hline \multicolumn{2}{|c|}{ Table 3. Basic Information of Respondents (N =322) } \\
\hline \multicolumn{2}{|c|}{ Percentage (\%) } \\
\hline \multirow{2}{*}{ Gender } & Male & 48.4 \\
\cline { 2 - 3 } & Female & 51.6 \\
\hline \multirow{3}{*}{ Level of Education } & $16-20$ & 12.4 \\
\cline { 2 - 3 } & $21-25$ & 86.3 \\
\cline { 2 - 3 } & $26-30$ & 1.2 \\
\cline { 2 - 3 } & Undergraduate & 95.7 \\
\cline { 2 - 3 } & Postgraduate & 2.5 \\
\cline { 2 - 3 } & Others & 1.9 \\
\hline
\end{tabular}


b. Rate among University Students Who Affected by COVID-19 or Faced COVID-19 Symptoms

This section of the questionnaire illustrates the rate of university students who were affected by COVID-19 or faced any symptoms. Figure- 1 depicts the proportion of the subject who was affected by COVID-19, where Figure- 2 represents the rate who were faced any symptoms.

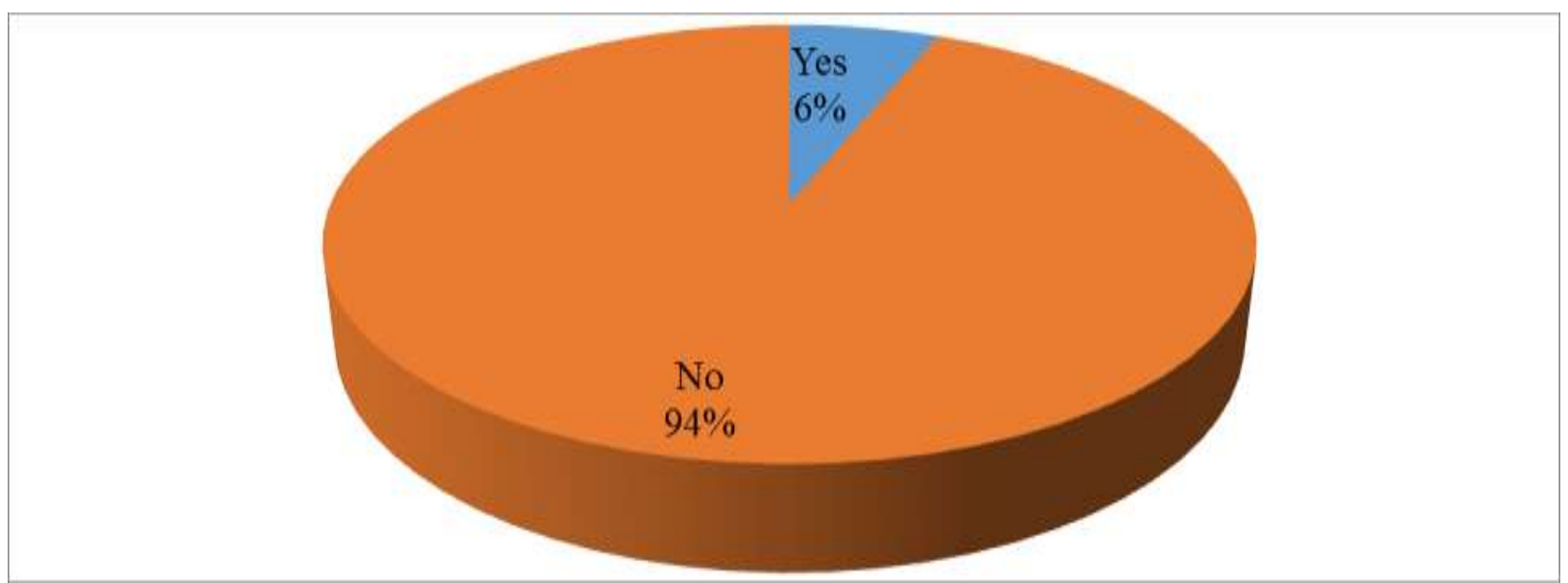

Figure 1. Affected by COVID-19 or Not

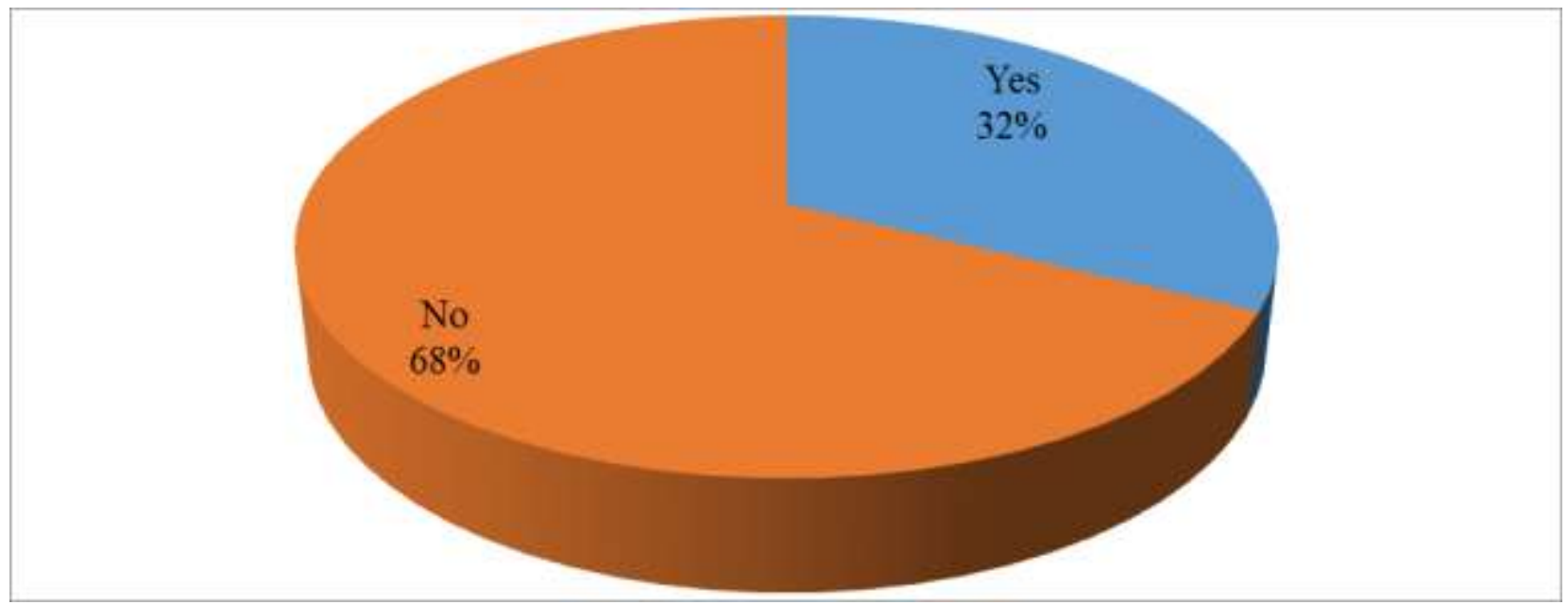

Figure 2. Faced COVID-19 Symptoms or Not

\section{c. University Students' Perception toward COVID-19 Vaccination Program}

The knowledge, perceptions, and attitudes of university students toward the COVID19 vaccination program were assessed in this portion of the questionnaire. The findings are shown in Tables 4-6. This segment's true picture is calculated by using the percentage. Furthermore, the mean denotes the overall average of subjects' responses, while the standard deviation indicates the variation in subjects' responses to a question (Biswas et al., 2020).

\begin{tabular}{|c|c|c|c|}
\hline \multicolumn{2}{|c|}{ Table 4. University Students' Knowledge towards COVID-19 Vaccination } \\
\hline Question & Yes & No & $\begin{array}{c}\text { May } \\
\text { be }\end{array}$ \\
\hline Q1. Do you think COVID-19 vaccines are effective? & 16.8 & 21.1 & $62.1 \%$ \\
\hline
\end{tabular}




\begin{tabular}{|l|r|r|r|}
\hline & $\%$ & $\%$ & \\
\hline $\begin{array}{l}\text { Q2. The COVID-19 vaccine can create long term physical } \\
\text { problems }\end{array}$ & Yes & No & $\begin{array}{r}\text { Don't } \\
\text { know }\end{array}$ \\
\hline & True & False & $\begin{array}{r}16.8 \\
\text { Don't } \\
\text { know }\end{array}$ \\
\hline Q3. This vaccine has the potential some side effects & $\begin{array}{r}65.8 \\
\%\end{array}$ & $2.5 \%$ & $31.7 \%$ \\
\hline
\end{tabular}

Table 5. University Students' Perception towards COVID-19 Vaccination

\begin{tabular}{|c|c|c|c|c|c|}
\hline Question & $\begin{array}{l}\text { Ag } \\
\text { ree }\end{array}$ & $\begin{array}{c}\text { Neu } \\
\text { tral }\end{array}$ & $\begin{array}{l}\text { Disa } \\
\text { gree }\end{array}$ & $\begin{array}{c}\text { Me } \\
\text { an }\end{array}$ & $\begin{array}{c}\text { Std. } \\
\text { Deviatio } \\
\text { n }\end{array}$ \\
\hline $\begin{array}{l}\text { Q4. I am satisfied with the government policy } \\
\text { towards COVID-19 vaccination program }\end{array}$ & $\begin{array}{l}34 . \\
8 \%\end{array}$ & $\begin{array}{r}46.0 \\
\%\end{array}$ & $\begin{array}{r}19.3 \\
\%\end{array}$ & $\begin{array}{r}2.1 \\
6\end{array}$ & .720 \\
\hline Q5. I am concerned about the COVID-19 pandemic & $\begin{array}{l}87 . \\
6 \%\end{array}$ & $\begin{array}{r}9.9 \\
\%\end{array}$ & $2.5 \%$ & $\begin{array}{r}2.8 \\
5\end{array}$ & .421 \\
\hline $\begin{array}{l}\text { Q6. I think that the COVID-19 vaccine is safe and } \\
\text { effective }\end{array}$ & $\begin{array}{l}20 . \\
5 \%\end{array}$ & $\begin{array}{r}57.8 \\
\%\end{array}$ & $\begin{array}{r}21.7 \\
\%\end{array}$ & $\begin{array}{r}1.9 \\
9\end{array}$ & .651 \\
\hline Q7. I want to take vaccine as soon as possible & $\begin{array}{l}36 . \\
0 \%\end{array}$ & $\begin{array}{r}31.7 \\
\%\end{array}$ & $\begin{array}{r}32.3 \\
\%\end{array}$ & $\begin{array}{r}2.0 \\
4\end{array}$ & .827 \\
\hline $\begin{array}{l}\text { Q8. I should aware and motivate people to take } \\
\text { vaccine }\end{array}$ & $\begin{array}{l}39 . \\
8 \%\end{array}$ & $\begin{array}{r}52.2 \\
\%\end{array}$ & $8.1 \%$ & $\begin{array}{r}2.3 \\
2\end{array}$ & .616 \\
\hline $\begin{array}{l}\text { Q9. I think vaccination will help to stop spreading } \\
\text { COVID-19 }\end{array}$ & $\begin{array}{l}36 . \\
0 \%\end{array}$ & $\begin{array}{r}41.6 \\
\%\end{array}$ & $\begin{array}{r}22.4 \\
\%\end{array}$ & $\begin{array}{r}2.1 \\
4\end{array}$ & .753 \\
\hline
\end{tabular}

Table 6. University Students' Attitude towards COVID-19 Vaccination

\begin{tabular}{|l|r|r|}
\hline \multicolumn{3}{|c|}{ Table 6. University Students' Attitude towards COVID-19 Vaccination } \\
\hline \multicolumn{1}{|c|}{ Question } & Yes & \multicolumn{1}{|c|}{ No } \\
\hline Q10. I try to avoid crowded places & $93.2 \%$ & $6.8 \%$ \\
\hline Q11. I try to maintain social distancing from people & $91.9 \%$ & $8.1 \%$ \\
\hline $\begin{array}{l}\text { Q12. I prefer to visit the hospital for test and treatment when I see } \\
\text { symptoms of COVID-19 }\end{array}$ & $70.8 \%$ & $\begin{array}{r}29.2 \\
\%\end{array}$ \\
\hline $\begin{array}{l}\text { Q13. I wash my hands or sanitize them before touching face or eyes or } \\
\text { after returning home }\end{array}$ & $92.5 \%$ & $7.5 \%$ \\
\hline $\begin{array}{l}\text { Q14. I'm hesitant to get the COVID-19 vaccine because I'm unfamiliar } \\
\text { with it. }\end{array}$ & $68.9 \%$ & True \\
\hline $\begin{array}{l}\text { Q15. I'm hesitant to get the COVID-19 vaccine because I'm concerned } \\
\text { about the potential side effects. }\end{array}$ \\
\hline
\end{tabular}




\subsection{Dis cussion}

At present especially from the beginning of the year 2020 to now, people around the globe are fighting this deadliest pandemic. People from all corners of the world are suffering a lot as well as the life of the majority population is becoming difficult because of it. University students are not the exception in this case. Their daily life especially their career is being seriously hampered due to COVID-19. Among the respondents cum university students, $48.4 \%$ are male and $51.6 \%$ are female as shown in Table 3 . Table 3 represents the age level and level of education of the students, in which $12.4 \%$ are aged 16-20 years whether $86.3 \%$ belong to $21-25$ years and remaining $1.2 \%$ come from $26-30$ years age group, and the majority of the respondents $(95.7 \%)$ are currently studying at undergraduate level whether $2.5 \%$ come from postgraduate level and the remaining $(1.9 \%)$ belong to others.

Figure- 1 demonstrates that only $6.0 \%$ of all respondents were affected by COVID-19 where more than ninety percent $(94.0 \%)$ of respondents were not infected by it. On the other hand, 32.0\% of respondents, as figured out in Figure-2, faced COVID-19 symptoms and this ratio is more than five times of confirmed cases especially affected by COVID-19 where symptoms were not found among $68.0 \%$ respondents represent more than two-third portion $(68.0 \%)$ of all respondents. So, it is a matter of hope that, university students as well as the young population, because all the respondents of this study belong to the 16-30 years age group, are being less infected by COVID-19 despite showing symptoms among themselves.

Nowadays, almost all the people from all spheres of the world irrespective of their age, religion, race, profession are discussing COVID-19 and taking preventive measures for avoiding being infected. Besides, many people are also expressing their opinion regarding the COVID-19 vaccination program. This study has tried to figure out the psychological factor such as knowledge, attitude, and perception of the university students' towards the vaccination program in the context of Bangladesh, as shown in Table-4, Table5 , and Table-6 respectively.

In response to knowledge-related questions as displayed in Table-4, only $16.8 \%$ of university students expressed that vaccines are effective, while $21.1 \%$ of respondents expressed their faith in the ineffectiveness of vaccines and nearly two-third of total respondents $(62.1 \%)$ didn't respond clearly but they think that it may be effective. Moreover, around sixty percent $(65.8 \%)$ of university students showed their confusion about the vaccine which may create long-term physical problems, while $17.4 \%$ expressed a positive response in this case. On the other hand, almost two-thirds of all respondents $(65.8 \%)$ told that the COVID-19 vaccine has the potential for some side effects, while only $2.5 \%$ believed that the vaccine has no potential for side effects, and $31.7 \%$ of respondents had no sense about the issue.

In a matter related to perception towards COVID-19 vaccination program as demonstrated in Table-5, 34.8\% of university students agreed that they were satisfied with the government policy towards the vaccination program, while $46.0 \%$ respondents were neutral and $19.3 \%$ disagreed with the policy taken by the government for this case. The vast majority of respondents $(87.6 \%)$ agreed that they are concerned about the pandemic, while only $2.5 \%$ of university students were not concerned about this matter at all. When asked the respondents about their thought or perceptions of the COVID-19 vaccine's safety and effectiveness, $20.5 \%$ agreed that the vaccine is safe and effective, while $57.8 \%$ of respondents kept themselves neutral in this case and $21.7 \%$ disagreed on this opinion. More than one-third of the total respondents $(36.0 \%)$ were interested to take the vaccine as soon as possible, while $31.7 \%$ were neutral and $32.3 \%$ shown an unwillingness to take the 
vaccine as early as possible. Around forty percent (39.8\%) respondents claimed that they could take apart to aware and motivate people towards the vaccine, while more than half of all respondents $(52.2 \%)$ were neutral in this matter and less than ten percent $(8.1 \%)$ respondents disagreed on raising awareness and motivating other people for the vaccine. Furthermore, $36.0 \%$ of university students believed that vaccination will help to stop spreading the virus, while $41.6 \%$ kept themselves neutral in this case and $22.4 \%$ of respondents didn't think vaccination will help to halt spreading COVID-19.

In reply to attitude related questions as presented in Table-6, almost all the respondents $(93.2 \%)$ opined that they try to avoid crowded places as well as $92.5 \%$ washed their hands or sanitized themselves before touching face or eyes or after returning home, while the ratio was $91.9 \%$ in the matter related to maintaining social distancing from people. More than seventy percent $(70.8 \%)$ of respondents preferred to visit the hospital for test and treatment for having symptoms of COVID-19, while the remaining thought just the opposite in this case. The study also identified some psychological dilemmas among respondents regarding being vaccinated for preventing the pandemic. Primary data shows that $68.9 \%$ of respondents expressed their hesitancy to take the vaccine because they don't know enough about it, while this ratio was $77.6 \%$ regarding their suspicion about the COVID-19 vaccine because they are afraid of the side effects.

So, the concerned authorities should take note of the issues discussed above and avail necessary arrangements for raising awareness about the COVID-19 vaccination program among the mass people so that they may feel safe at the time of being vaccinated. Besides, the Government of Bangladesh should also ensure vaccination for all the citizens as early as possible which is the need of the hour to fight against the pandemic. If the government can do so, normalcy in the daily life of the people of Bangladesh will be in reality.

\section{Conclusion}

According to databd, nearly $16 \%$ people of the total population of Bangladesh are tertiary-level students and they are the upcoming future of Bangladesh. The major intention of this paper is to measure the youth's perception regarding vaccination. Also, the survey demonstrates that the lack of proper knowledge and awareness creates a barrier in the mindset of students to take the vaccination. The findings indicate that the policymaker and health worker need to rethink the vaccination strategy and pay more effort to spread the effectiveness of the vaccine and clear the rumor of vaccines' side effect as the proportion of the university students is the subset of the total population. Moreover, the availability of transparent information about vaccine efficiency and safety can play a key role for everyone to be encouraged to take vaccination without any doubt.

\section{References}

Ali, S. H., Foreman, J., Tozan, Y., Capasso, A., Jones, A. M., \& DiClemente, R. J. (2020). Trends and predictors of COVID-19 information sources and their relationship with knowledge and beliefs related to the pandemic: nationwide cross-sectional study. JMIR public health and surveillance, 6(4), e21071.

Asante, L. A., \& Mills, R. O. (2020). Exploring the socio-economic impact of COVID-19 pandemic in marketplaces in urban Ghana. Africa Spectrum, 55(2), 170-181. 
Bhartiya S, Kumar N, Singh T, Murugan S, Rajavel S, Wadhwani M. (2021). Knowledge, attitude and practice towards COVID-19 vaccination acceptance in West India. Int $\mathbf{J}$ Community Med Public Health 2021;8:1170-6

Biswas, B., Roy, S. K., \& Roy, F. (2020). Students Perception of Mobile Learning during COVID-19 in Bangladesh: University Student Perspective. Aquademia, 4(2), ep20023. https://doi.org/10.29333/aquademia/8443

Chan, E. Y. Y., Cheng, C. K. Y., Tam, G. C. H., Huang, Z., \& Lee, P. Y. (2015). Willingness of future $\mathrm{A} / \mathrm{H} 7 \mathrm{~N} 9$ influenza vaccine uptake: a cross-sectional study of Hong Kong community. Vaccine, 33(38), 4737-4740.

Felter, C. (2021). What to Know About the Global COVID-19 Vaccine Rollout So Far. Council on Foreign Relations.

Haque, A. (2020). The COVID-19 pandemic and the public health challenges in Bangladesh: a commentary. Journal of Health Research.

Harapan, H., Anwar, S., Dimiati, H., Hayati, Z., \& Mudatsir, M. (2019). Diphtheria outbreak in Indonesia, 2017: An outbreak of an ancient and vaccine-preventable disease in the third millennium. Clinical Epidemiology and Global Health, 7(2), 261262.

Hassan, A. M. (2021). Covid-19 vaccination: How's Bangladesh doing compared to the rest of the world? The Daily Star. Retrived on 23 february 2021 from https://www.thedailystar.net/coronavirus-deadly-new-threat/news/covid-19vaccination-hows-bangladesh-doing-compared-the-rest-the-world-2049289

Holder, J. (2021)., 18 march, 2021). Tracking Coronavirus Vaccinations Around the World. The New York times. Retrived on 18 March 2021 from https://www.nytimes.com/interactive/2021/world/covid-vaccinations-tracker.html

Islam, M. S., Siddique, A. B., Akter, R., Tasnim, R., Sujan, M. S. H., Ward, P. R., \& Sikder, M. T. (2021). Knowledge, attitudes and perceptions towards COVID-19 vaccinations: a cross-sectional community survey in Bangladesh. medRxiv. https://doi.org/10.1101/2021.02.16.21251802

Khalil, N. S., Al-Yuzbaki, D. B., \& Tawfeeq, R. S. (2020). COVID-19 knowledge, attitude and practice among medical undergraduate students in Baghdad City. EurAsian Journal of BioSciences, 14(2), 4179-4186.

Lazarus, J. V., Ratzan, S., Palayew, A., Gostin, L. O., Larson, H. J., Rabin, K., ... \& ElMohandes, A. (2020). Hesitant or not? A global survey of potential acceptance of a COVID-19 vaccine. medRxiv.

Lucia, V. C., Kelekar, A., \& Afonso, N. M. (2020). COVID-19 vaccine hesitancy among medical students. Journal of Public Health.

Mannan, D. K. A., \& Farhana, K. M. (2020). Knowledge, Attitude and Acceptance of a COVID-19 Vaccine: A Global Cross-Sectional Study. International Research Journal of Business and Social Science, 6(4).

Our World in Data (2021). https://github.com/owid/covid-19 data/blob/master/public/data/vaccinations/country_data/Bangladesh.cs v-

Pogue, K., Jensen, J. L., Stancil, C. K., Ferguson, D. G., Hughes, S. J., Mello, E. J., ... \& Poole, B. D. (2020). Influences on attitudes regarding potential COVID-19 vaccination in the United States. Vaccines, 8(4), 582.

Reiter, P. L., Pennell, M. L., \& Katz, M. L. (2020). Acceptability of a COVID-19 vaccine among adults in the United States: How many people would get vaccinated? Vaccine, 38(42), 6500-6507

Siegrist, M., \& Zingg, A. (2014). The role of public trust during pandemics: Implications for crisis communication. European Psychologist, 19(1), 23. 
Synnott, C. K. (2020). College Students' COVID-19 Vaccine Hesitancy. https://orcid.org/0000-0002-6960-0093

The Daily Star (2021). Bharat Biotech's Coronavirus Vaccine: Concerns grow in India over safety. Available: https:/www.thedailystar.net/frontpage/news/bharat-biotechscoronavirus-vaccineconcerns-grow-india-over-safety-2028549

The Times of India. (2021). Bangladesh Kicks off Countrywide Vaccination Drive. https://timesofindia.indiatimes.com/world/south-asia/covid-19-bangladesh-kicks-offcountrywide-vaccination-drive/articleshow/80735693.cms

Uttam, S. (2021). Poor response to Bangladesh's Covid-19 vaccination drive. February 08, 2021, UCAnews. Retrived on 8 february 2021 from https://www.ucanews.com/news/poor-response-to-bangladeshs-covid-19vaccination-drive/91329

Van Doremalen, N., Bushmaker, T., Morris, D. H., Holbrook, M. G., Gamble, A., Williamson, B. N., \& Munster, V. J. (2020). Aerosol and surface stability of SARSCoV-2 as compared with SARS-CoV-1. New England journal of medicine, 382(16), 1564-1567.

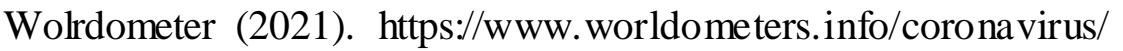

World Health Organization (2020) Coronavirus disease (COVID-19): Situation report 168. Available at: https://www.who.int/docs/default-source/coronaviruse/situationreports/20200706-covid-19-sitrep-168.pdf?sfvrsn=7fed5c0b_2 